\title{
HUBUNGAN ANCAMAN YANG DIRASAKAN DENGAN UPAYA MENCEGAH BAHAYA ROKOK BAGI KESEHATAN REMAJA DI DESA HUTARAJA KECAMATAN SIABU KABUPATEN MANDAILING NATAL TAHUN 2015
}

\author{
Yetti Lusiani, Hasny, Sondang, Salwah \\ Jurusan Keperawatan Gigi Politeknik Kesehatan Kemenkes Medan
}

\begin{abstract}
Smoking tends to be favored by men, including women. "89\% of smokers are adolescences who are influenced by advertisement," said the Secretary General of Child Protection, Arist Merdeka Sirait. The National Socio-Economic Survey in 2009 states that the highest adolescence group between 15 to 19 years old that smoke reaches to 63.7\%.The research used analytic method with cross sectional design. The samples were 30 adolescences, taken by using simple random sampling technique. The data consisted of primary and secondary data. Primary data were gathered by using questionnaires about the threat and effort to forestall the danger of smoking. The gathered data were analyzed by using univatriate analysis and bivatriate analysis with chi square statistic test. The result of the research showed that 22 respondents (73.3\%) were threatened by the danger of smoking, and 8 respondents (26.7\%) were not, while 8 respondents (26.7\%) attempted to forestall the danger of smoking for dental health and 22 respondents (73.3\%) did not.The result of chi square test showed that there was no significant correlation between the variable of threat and the variable of effort to forestall the danger of smoking for adolescences' dental health $(p=3.55)$. The threat felt by adolescences did not influence their effort to forestall the danger of smoking for their dental health.
\end{abstract}

Keywords : Threat, Effort to Forestall, Danger of Smoking, Dental Health

\section{PENDAHULUAN}

Dunia moderen saat ini tak ada yang kontrofersional daripada rokok dan perokok. Bahwa industri rokok menggalakkan kegiatan ekonomi secara langsung maupun tak langsung, yaitu ke hulu (agrobisnis, tembakau, kertas, dan lain sebagainya), ke arah samping (industri aromatika, kertas, cetakan kemasan dan sebagainya), ke arah hilir (aktifitas promosi, pemasaran,dan lain-lain), sudah dimaklumi secara luas. Rokok memberikan salah satu produk yang cukup unik (terutama cara mengkonsumsinya), karena produk ini merupakan kepuasan kepada konsumen melalui asap, hasil pembakaran tembakau dan campuran lain di dalamnya yang dihisap melalui mulut. Saat ini yang menkomsumsi rokok relatif tinggi dikalangan masyrakat baik di kalangan remaja maupun dikalangan orang dewasa. Bahkan oleh sebagian orang, rokok sudah menjadi kebutuhan hidup yang tidak bisa ditinggalkan begitu saja dalam kehidupan sehari-hari. Sehingga kebiasaan merokok telah menjadi budaya manusia di berbagai belahan dunia.

Masa remaja merupakan masa ketika seorang anak mengalami perubahan fisik, psikis, dan pematangan fungsi seksual. Remaja dalam perkembangannya, sering kali memprihatinkan selama tahun-tahun awal remaja. Salah satu sumber keprihatinan tersebut adalah perubahan bentuk tubuh yang tidak sesuai dengan standar budaya yang berlaku sebagai akibat dari perkembangan seksual sekunder yang di alami remaja. Bila penerimaan remaja putri rendah, maka remaja merasa prihatin dan gelisah akan tubuhnya yang berubah dan merasa tidak puas dengan penampilan dirinya (Sriyani, 2010).

Mayoritas perokok $89 \%$ adalah remaja, hal ini terdorong oleh iklan untuk merokok, ungkap sekjen pelindung anak, Arist Merdeka Sirait menyebutkan. Dari Survei Sosial Ekonomi Nasional tahun 2009, usia mulai merokok di Tanah Air yang tertinggi ada di kelompok usia remaja yaitu di antara usia 15-19 tahun jumlahnya mencapai $63,7 \%$. Latar belakang alasannya mengkonsumsi rokok beraneka ragam, di kalangan remaja dan dewasa pria faktor gengsi agar disebut pria jagoan menjadi alasan utama, sedangkan di kalangan orang tua stres dan ketagihan adalah faktor penyebab ingin merokok. Tanpa alasan yang jelas seseorang merokok setelah makan, setelah minum kopi atau teh, bahkan sambil kerja pun sering kali diselingi dengan rokok.

Telah banyak riset yang membuktikan bahwa rokok dapat menyebabkan kecanduan. Disamping itu rokok juga dapat menyebabkan banyak tipe kanker, penyakit jantung, penyakit pernapasan, penyakit pencernaan, efek buruk bagi kelahiran, dan emfisema. Tidak hanya itu rokok juga dapat menimbulkan iritasi 
terhadap gusi, dan secara tidak langsung juga dapat menyebabkan kanker mulut (Muhammad Jaya, 9 Mei 2008).

Rongga mulut merupakan awal terjadinya zat-zat hasil pembakaran rokok. Temperatur rokok pada bibir adalah $30^{\circ} \mathrm{C}$, sedangkan ujung rokok yang terbakar bersuhu $900^{\circ} \mathrm{C}$. Asap panas yang berhembus terus menerus kedalam rongga mulut merupakan rangsang panas yang menyebabkan perubahan aliran darah yang mengurangi pengeluaran air ludah. Akibat rongga mulut menjadi kering dan kelebihan-aerob (suasana bebas zat asam) sehingga tumbuhnya bakteri an-aerob dalam plak .

Perokok lebih besar terinfeksi bakteri penyakit jaringan pendukung gigi di bandingkan bukan perokok. Pengaruh asap rokok secara langsung adalah iritasi terhadap gusi, dan secara tidak langsung adalah melalui produk-produk rokok seperti nikotin yang sudah masuk melalui aliran darah dan ludah. Jaringan pendukung gigi yang sehat seperti gusi, selaput gigi, segmen gigi, dan tulang tempat tertanamnya gigi menjadi rusak karena ketergantungannya fungsi normal mekanisme pertahanan tubuh terhadap infeksi, dan dapat merangsang tubuh untuk menghancurkan jaringan sehat di sekitarnya.

Tahun 2004 hampir tiga perempat dari rumah tangga di Indonesia memiliki anggaran belanja rokok, artinya minimal ada satu perokok di dalam rumah,' ujur Widyastuti ia menambahkan, sedikitnya $65 \%$ remaja berusia 13 - 15 terpapar asap rokok di dalam rumah.

Tidak seharusnya kita bangga dengan "prestasi", yang kita miliki oleh karena itu serentetan penyakit yang berujung kematian menghantui. Dalam kandungan satu rokok setidaknya terdapat 4.000 zat kimia dan 43 zat karsinogenik, dan $40 \%$ beracun seperti hidrokarbon, karbon monoksida, logam berat, tar, dan nikotin yang berefek candu.

Setiap tahunnya angka kematian di dunia mencapai 5 juta orang diakibatkan berbagai penyakit disebabkan rokok, seperti kanker paru- paru dan penyakit jantung.

Berdasarkan survei WHO, kematian pada 2030 mencapai 10 juta orang, ujar Direktur Pengadilan Penyakit Direktorat Pengendalian Penyakit dan Penyehatan Lingkungan Depertemen Kesehatan Tjandra Yogha Aditaman. Di Indonesia, menurut Demografi Universitas Indonesia, sebanyak 427.948 orang meninggal di Indonesia rata - rata per tahunnya akibat berbagai penyakit yang disebabkan rokok.

Gusi seorang perokok cendrung mengalami penebalan lapisan tanduk. Daerah yang mengalami penebalan ini terlihat lebih kasar dibandingkan jaringan disekitarnya dan berkurang kekenyalannya. Penyempitan pembuluh darah yang disebabkan nikotin mengakibatkan kekurangannya aliran darah di gusi sehingga meningkatkan kecendrungan timbulnya penyakit gusi.

Penyakit jaringan pendukung gigi yang parah, kerusakan tulang penyokong gigi, dan tanggalnya gigi lebih banyak terjadi pada perokok daripada bukan perokok. Pada perawatan penyakit jaringan pendukung gigi, pasien perokok memerlukan perawatan yang lebih luas dan lebih lanjut. Perlekatan jaringan ikat dan serat-serat kolagen terhambat, sehingga proses penyembuhan dan generasi jaringan selama perawatan terganggu, padahal pasien bukan perokok dan pada keadaan yang sama cukup di lakukan perawatan standar seperti pembersihan plak dan karang gigi. (Dyayadi M.T, 2009).

Keparahan penyakit yang timbul dari tingkat sedang hingga lanjut berhubungan langsung dengan banyaknya rokok yang diisap setiap hari beberapa lama atau beberapa tahun seseorang menjadi perokok,dan status merokok itu sendiri, apakah masih merokok sehingga sekarang atau berhenti. Hampir setiap konser musik dan event olahraga Indonesia disponsori oleh industri rokok. Dalam event rokok tersebut mereka membagikan rokok gratis atau mudah mendapatkan dengan menukarkan potongan tiket masuk acara tersebut. Kedekatan remaja dengan rokok tidak hanya dikarenakan gencarnya iklan rokok di media, tetapi mulai dari lingkungan terkecilnya (keluarga).

Survey awal yang telah dilakukan di Desa Hutaraja Kecamatan Siabu Kabupaten Mandailing Natal tahun 2015 banyak ditemukan pemasalahan banyaknya masalah gigi yang kotor, disebabkan karena mengkonsumsi rokok dan tidak membersihkan karang gigi. Berdasarkan uraian diatas, maka penulis tertarik untuk meneliti tentang hubungan ancaman yang dirasakan dengan upaya mencegah bahaya rokok bagi kesehatan gigi di Desa Hutaraja Kecamatan Siabu Kabupaten Mandailing Natal.

\section{Tujuan Penelitian}

Adapun tujuan dari penelitian ini adalah untuk mengetahui tentang hubungan ancaman yang dirasakan dengan upaya mencegah bahaya rokok bagi kesehatan gigi di Desa Hutaraja Kecamatan Siabu Kabupaten Mandailing Natal tahun 2015.

1. Untuk mengetahui ancaman yang dirasakan dengan bahaya rokok atau tidak merokok bagi kesehatan remaja.

2. Untuk mengetahui upaya mencegah bahaya rokok bagi remaja di Desa Hutaraja Kecamatan Siabu Kabupaten Mandailing Natal.

\section{Hipotesis}

Hipotesis adalah jawaban sementara dari suatu penelitian. Penelitian ini akan membuktikan hubungan Ancaman Yang Dirasakan Dengan Upaya Mencegah Bahaya Rokok Bagi Kesehatan Gigi Remaja.

Adapun hipotesis penelitian yang akan dibuktikan adalah :

Ho : Tidak ada hubungan antara Ancaman Yang Dirasakan Dengan Upaya Mencegah

Ha : Adanya hubungan antara Ancaman Yang Dirasakan Dengan Upaya Mencegah Bahaya Rokok Bagi Kesehatan Gigi Remaja

\section{Manfaat Penelitian}

1. Penelitian ini di harapkan bisa menjadi sumber informasi bagi responden tentang bahaya merokok bagi kesehatan gigi untuk menyelesaikan masalah kesehatan gigi. 
2. Penelitan ini di harapkan sebagai perbandingan dan referensi bagi peneliti selanjutnya

3. Penelitian di harapkan bisa menjadi bahan bacaan bagi mahasiswa Politeknik Kesehatan Kemenkes Medan Jurusan Kepewatan Gigi untuk menambah pengetahuan.

\section{Metode Penelitian \\ Jenis Penelitian}

Jenis penelitian ini adalah analitik dengan metode survey untuk mengetahui. Hubungan Ancaman yang di Rasakan Dengan Upaya Mencegah Bahaya Rokok. Bagi kesehatan Gigi di Desa Hutaraja Kecamatan Siabu Kabupaten Mandailing Natal Tahun 2015. Desain penelitian ini adalah cross sectional yang artinya penelitian yang dilakukan pada satu waktu dan satu kali saja.

\section{HASIL}

\section{A.1 Analisi Univariat}

A.1.1 Distribusi Responden Berdasarkan Ancaman yang Dirasakan dengan Bahaya Rokok Bagi Kesehatan Gigi Remaja Di Desa Hutaraja Kecamatan Siabu Kabupaten Mandailing Natal Tahun 2015

Berdasarkan tabel 1, distribusi responden berdasarkan kategorisasi terancam dengan bahaya rokok sebanyak 22 responden $(73,3 \%)$ sedangkan tidak terancam sebanyak 8 responden $(26,7 \%)$.

Tabel 1. Distribusi Responden Berdasarkan Ancaman Yang Dirasakan Dengan Bahaya Rokok Bagi Kesehatan Gigi Remaja Di Desa Hutaraja Kecamatan Siabu Kabupaten Mandailing Natal Tahun 2015

\begin{tabular}{lcc}
\hline $\begin{array}{c}\text { Ancaman yang } \\
\text { Dirasakan }\end{array}$ & Frekuensi & Persentase \\
\hline Terancam & 22 & 73,3 \\
Tidak Terancam & 8 & 26,7 \\
\hline Total & $\mathbf{3 0}$ & $\mathbf{1 0 0 , 0}$ \\
\hline
\end{tabular}

A.1.2 Distribusi Reponden Berdasarkan Kategori Upaya Mencegah Bahaya Rokok Bagi Kesehatan Gigi Remaja Di Desa Hutaraja Kecamatan Siabu Kabupaten Mandailing Natal Tahun 2015

Dari hasil penelitian diperoleh bahwa responden yang mempunyai upaya mencegah bahaya rokok bagi kesehatan gigi remaja sebanyak 8 responden $(26,7 \%)$ sedangkan tidak ada upaya sebanyak 22 responden $(73,3 \%)$.
Tabel 2. Distribusi Responden Berdasarkan Kategori Upaya Mencegah Bahaya Rokok Bagi Kesehatan Gigi Remaja Di Desa Hutaraja Kecamatan Siabu Kabupaten Mandailing Natal Tahun 2015

\begin{tabular}{lcc}
\hline $\begin{array}{l}\text { Upaya } \\
\text { Mencegah }\end{array}$ & Frekuensi & Persentase \\
\hline Ada Upaya & 8 & 26,7 \\
Tidak Ada & 22 & 73,3 \\
Upaya & & \\
\hline Total & $\mathbf{3 0}$ & $\mathbf{1 0 0 , 0}$ \\
\hline
\end{tabular}

\section{A.2 Analisis Bivariat}

Untuk mengetahui hubungan dua variabel yaitu antara satu variabel independent dengan satu variabel dependent maka digunakanlah analisis bivariat. Pada penelitian ini analisis bivariat yang digunakan adalah $\mathrm{Uji}$ chi square, masing-masing variabel independen dan variabel dependen yang sudah dikategorikan diuji apakah ada hubungan antara variabel ancaman yang dirasakan dengan upaya mencegah bahaya rokok bagi kesehatan gigi pada remaja. Jika nilai $\mathrm{p}<0,05$ maka Ho ditolak atau hipotesis penelitian diterima, yang artinya ada hubungan antara variabel independen dan dependen.

\subsection{Hubungan Ancaman Yang Dirasakan Dengan} Upaya Mencegah Bahaya Rokok Bagi Kesehatan Gigi Remaja Di Desa Hutaraja Kecamatan Siabu Kabupaten Mandailing Natal Tahun 2015

Hasil uji statistik dengan menggunakan uji ChiSquare dengan IK 95\% maka didapat nilai $\mathrm{p}=0,355$ $(\mathrm{p}>0,05)$ artinya tidak ada hubungan yang signifikan antara ancaman yang dirasakan dengan upaya mencegah bahaya rokok bagi kesehatan gigi pada remaja.

Tabel 3. Hubungan Ancaman Yang Dirasakan Dengan Upaya Mencegah Bahaya Rokok Bagi Kesehatan Gigi Remaja Di Desa Hutaraja Kecamatan Siabu Kabupaten Mandailing Natal Tahun 2015

\begin{tabular}{ccccc}
\hline \multirow{2}{*}{ Variabel } & \multicolumn{4}{c}{ Upaya Mencegah } \\
\cline { 2 - 5 } & $\begin{array}{c}\text { Tidak ada } \\
\text { Upaya }\end{array}$ & $\begin{array}{c}\text { Uda } \\
\text { Upaya }\end{array}$ & df & P \\
\hline Terancam & 5 & 17 & & \\
Variabel & & & 1 & 0,355 \\
Ancaman & & & &
\end{tabular}

Tidak terancam $\quad 3 \quad 5$

\section{PEMBAHASAN}

Rokok merupakan salah satu alat yang cendrung disukai kalangan pria, bahkan wanita.

Berdasarkan hasil analisa univariat tabel 1 membuktikan bahwa dari 30 remaja katagori terancam dengan bahaya rokok sebanyak 22 responden $(73,3 \%)$ 
sedangkan tidak terancam sebanyak 8 responden (26,7\%). Dari hasil analisa univariat tabel 2 membuktikan bahwa dari 30 remaja yang mengalami katagori upaya mencegah bahaya rokok bagi kesehatan gigi remaja sebanyak 8 responden $(26,7 \%)$ sedangkan tidak ada upaya sebanyak 22 responden $(73,3 \%)$.

Hasil analisa bivariat pada tabel 3 membuktikan bahwa ancaman yang dirasakan dengan upaya mencegah bahaya rokok terhadap kesehatan gigi remaja darihasil statistik Uji Square menunjukkan variabel hubungan ancaman tidak berhubungan signifikan dengan variabel upaya mencegah bahaya rokok terhadap kesehatan gigi remaja yaitu $(p=3.55)$. Hal ini membuktikan bahwa tidak ada hubungan ancaman yang dirasakan dengan upaya mencegah bahaya rokok bagi kesehatan gigi remaja di Desa Hutaraja Kecamatan Siabu Kabupaten Mandailing Natal.

Berdasarkan survey yang telah dilakukan sebelum melakuka penelitian bahwa di Desa Hutaraja Kecamatan Siabu Kabupaten Mandailing Natal tahun 2015 remaja lebih banyak mengkonsumsi rokok. Karena banyak diantara mereka yang mengkonsumsi rokok, meskipun banyak yang mengetahui bahaya merokok terhadap kesehatan gigi. Walaupun mereka merasa terancam akan bahaya dari rokok tapi mereka tetap mengkonsumsi rokok.

Merokok menjadi suatu kebutuhan dan selalu mereka butuhkan. Hal ini bisa dikarenakan memang dalam komposisi rokok itu sendiri ada zat yang membuat orang ketagihan untuk tetap merokok.

\section{SIMPULAN DAN SARAN}

\section{Simpulan}

Berdasarkan hasil dan pembahasan pada bab sebelumnya maka dapat disimpulkan, yaitu :

1. Distribusi responden berdasarkan kategorisasi terancam dengan bahaya rokok sebanyak 22 responden $(73,3 \%)$ sedangkan tidak terancam sebanyak 8 responden $(26,7 \%)$.

2. Distribusi responden yang mempunyai upaya mencegah bahaya rokok bagi kesehatan gigi remaja sebanyak 8 responden $(26,7 \%)$ sedangkan tidak ada upaya sebanyak 22 responden $(73,3 \%)$.

3. Ancaman Yang Dirasakan Dengan Upaya Mencegah Bahaya Rokok Bagi Kesehatan Gigi Remaja Di Desa Hutaraja Kecamatan Siabu Kabupaten Mandailing Natal tidak mempunyai hubungan yang signifikan dimana dari hasil Uji
Square didapatkan hasil nilai $\mathrm{p}=0,355(\mathrm{p} \geq 0,05)$ maka hipotesis nol (Ho) diterima yang berarti bahwa ancaman yang dirasakan tidak berpengaruh dengan upaya mencegah bahaya rokok bagi kesehatan gigi remaja.

\section{Saran}

1. Diharapkan pihak Kelurahan Hutaraja agar melakukan penyuluhan tentang bahaya rokok bagi kesehatan gigi. Bekerja sama dengan instansi kesehatan setempat.

2. Diharapkan remaja yang merokok di Kelurahan Hutaraja agar lebih memperhatikan kesehatan gigi.

3. Perlu adanya peningkatan sosialisasi dengan instansi setempat tentang bahaya rokok bagi kesehatan gigi.

\section{DAFTAR PUSTAKA}

Aditama,T.Y.,2013.Tuberkulosis, Rokok dan Perempuan. FKUI, Jakarta: Fakultas Kedokteran Universitas Jakarta UI

Aditama,T.Y, 2011. Rokok Dan Kesehatan. Jakarta: Universitas Indonesia ( UI -Press)

Albery, P dan Munafo,M.,2011.Psikologi Kesehatan Panduan Lengkap Dan Komprehensif Bagi Studi Psikologi Kesehatan. Yogyakarta: PalMall

Arikunto, S., 2006. Prosedur Penelitian Suatu Pendekatan Praktik.Jakarta: Rineka Cipta

Arikunto, S., 2013. Prosedur Penelitian Stuatu Pendekatan Praktik.Jakarta: Rineka Cipta

Dahlan,S., 2010. Besar Sampel dan Cara Pengambilan Sampel Dalam Penelitian Kedokteran Dan Kesehatan. Jakarta: Selemba Media

Jaya, M., 2009. Pembunuh Berbahaya Itu Bernama Rokok. Yogyakarta: Rizma

Notoatmodjo,S., 2010. Metodologi Penelitian Kesehatan. Jakarta: Rineka Cipta

Notoatmodjo, S., 2010. Ilmu Perilaku Kesehatan. Jakarta:Rineka Cipta

Nurhayati, I., 2015. Panduan Penyusunan Karya Tulis Ilmiah. Medan: Politeknik Kesehatan Kemenkes Medn.

Siswanto, et. al., 2014. Metodelogi Penelitian Kesehatan dan Kedokteran. Edisi 1. Karangkajen,Yogyakarta: Bursa Ilmu. 